\title{
Correlations between Diffusion Tensor Imaging (DTI) and Magnetic Resonance Spectroscopy ('H MRS) in schizophrenic patients and normal controls
}

\author{
Cheuk Y Tang*1,2,4, Joseph Friedman², Dikoma Shungu ${ }^{5}$, Linda Chang 6 , \\ Thomas Ernst ${ }^{6}$, Daniel Stewart ${ }^{2}$, Arash Hajianpour ${ }^{1}$, David Carpenter ${ }^{1}$, \\ Johnny Ng1, Xiangling Mao ${ }^{5}$, Patrick R Hof ${ }^{3}$, Monte S Buchsbaum², \\ Kenneth Davis ${ }^{2}$ and Jack M Gorman ${ }^{2}$
}

Address: ${ }^{1}$ Department of Radiology, Mount Sinai School of Medicine NY, NY 10029, USA, ${ }^{2}$ Department of Psychiatry, Mount Sinai School of Medicine NY, NY 10029, USA, ${ }^{3}$ Department of Neuroscience, Mount Sinai School of Medicine NY, NY 10029, USA, ${ }^{4}$ Department of Pathology, Mount Sinai School of Medicine NY, NY 10029, USA, 5 Department of Radiology, Weill Medical College of Cornell University, NY, NY 10021, USA and ${ }^{6}$ Department of Medicine, University of Hawaii, HI 96817, USA

Email: Cheuk Y Tang* - Cheuk.tang@mssm.edu; Joseph Friedman - jfriedman1@rcn.com; Dikoma Shungu - dcs4070@msn.com; Linda Chang - lchang@hawaii.edu; Thomas Ernst - tmernst@hawaii.edu; Daniel Stewart - Daniel.Stewart@mssm.edu; Arash Hajianpour - hajianpour@hotmail.com; David Carpenter - David.carpenter@mssm.edu; Johnny Ng - johnnycng@hotmail.com; Xiangling Mao - xim2004@med.cornell.edu; Patrick R Hof - Patrick.Hof@mssm.edu; Monte S Buchsbaum - Monte.Buchsbaum@mssm.edu; Kenneth Davis - Kenneth.Davis@mssm.edu; Jack M Gorman - jackgorm@gmail.com

* Corresponding author

Published: 19 June 2007

BMC Psychiatry 2007, 7:25 doi:10.1186/147/-244X-7-25
Received: 30 October 2006 Accepted: 19 June 2007

This article is available from: http://www.biomedcentral.com/I47I-244X/7/25

(c) 2007 Tang et al; licensee BioMed Central Ltd.

This is an Open Access article distributed under the terms of the Creative Commons Attribution License (http://creativecommons.org/licenses/by/2.0), which permits unrestricted use, distribution, and reproduction in any medium, provided the original work is properly cited.

\begin{abstract}
Background: Evidence suggests that white matter integrity may play an underlying pathophysiological role in schizophrenia. $\mathrm{N}$-acetylaspartate (NAA), as measured by Magnetic Resonance Spectroscopy (MRS), is a neuronal marker and is decreased in white matter lesions and regions of axonal loss. It has also been found to be reduced in the prefrontal and temporal regions in patients with schizophrenia. Diffusion Tensor Imaging (DTI) allows one to measure the orientations of axonal tracts as well as the coherence of axonal bundles. DTI is thus sensitive to demyelination and other structural abnormalities. DTI has also shown abnormalities in these regions.
\end{abstract}

Methods: MRS and DTI were obtained on 42 healthy subjects and 40 subjects with schizophrenia. The data was analyzed using regions of interests in the Dorso-Lateral Prefrontal white matter, Medial Temporal white matter and Occipital white matter using both imaging modalities.

Results: NAA was significantly reduced in the patient population in the Medial Temporal regions. DTI anisotropy indices were also reduced in the same Medial Temporal regions. NAA and DTIanisotropy indices were also correlated in the left medial temporal region.

Conclusion: Our results implicate defects in the medial temporal white matter in patients with schizophrenia. Moreover, MRS and DTI are complementary modalities for the study of white matter disruptions in patients with schizophrenia. 


\section{Background}

Alterations in connectivity between brain regions including the frontal lobe, basal forebrain and limbic system, have been proposed as network deficits in schizophrenia [1-6]. Connections between the prefrontal cortex (PFC) and other cortical and subcortical regions implicated in the pathophysiology of schizophrenia suggest that a white matter abnormality in this region could have widespread consequences for neural connectivity in brain regions that are critical to the core symptoms of schizophrenia. The finding of increased neuronal density [7-13] is consistent with the notion that the integrity of white matter tracts is compromised. In addition, MRI evidence for decreased global [14-16], prefrontal [15,17-21] and temporal $[15,21]$ white matter in schizophrenia is quite convincing. A meta-analysis of studies of white matter volumes in schizophrenia reveals a reduction of approximately $2 \%$, with the greatest differences of approximately $5 \%$ in medial temporal lobe structures [14]. Indeed, regional rather than global reductions are far more relevant to the question of the origins of disconnectivity and hence of particular interest in the presentation of symptoms. For example, volume reductions in the white matter of PFC, repeatedly found in schizophrenia [17-20], are associated with the presentation of negative symptoms $[18,20]$.

Both MRS [22,39,41,42,44,46,23-27] and DTI [28-34] have been used extensively to study white matter abnormalities in patients with schizophrenia. The results of these two techniques may reflect different mechanisms of abnormal pathologies. MRS measurements are determined by biochemical profiles of the underlying pathologies, whereas DTI is more sensitive to structural differences.

Magnetic resonance spectroscopy allows one to quantify the concentrations of various metabolites in the brain. $\mathrm{N}$ acetylaspartate (NAA) is the most prominent metabolite detected in the normal human brain. NAA serves as a neuronal marker and is only present in mature neurons. Some studies have also shown the presence of NAA in oligodendrocyte-2A progenitor cells [35]. NAA has been shown to be decreased in well-known demyelinating diseases such as multiple sclerosis (MS) and progressive multifocal leukoencephalopathy (PML) and it is thought to be associated with axonal injury [36]. Decreased NAA in patients with schizophrenia has been found in the cerebellum [37], thalamus [23,38-44], dorso-lateral prefrontal cortex (DLPFC) [23,42-44], anterior cingulate [45], and medial temporal lobe $[24-27,46,47]$. Reduction in NAA may signify structural abnormality or reduced viability of the underlying neurons [35,48]. Given these results we have acquired MRS data on the DLPFC white matter, medial temporal (MT) white matter and on the occipital (OC) white matter as a reference.
Diffusion tensor imaging allows one to quantify the integrity of densely packed fiber bundles such as axonal tracts and to measure the orientation of such bundles [49-53]. DTI probes the microstructure of white matter by measuring the anisotropy of self-diffusion of water molecules in the restricted compartments of axonal tracts. Two quantitative measures can be obtained from DTI: anisotropy indices and fiber tract orientations. Anisotropy indices such as relative anisotropy (RA) and fractional anisotropy (FA) $[49,53]$ measure the amount of coherence of water diffusion which putatively reflects the amount of myelination in axonal bundles or the coherence of fiber tracts. The same dataset also provides information on the threedimensional orientation of the anisotropy and can be used to study fiber tract connectivity [54-56]. Previous DTI studies have shown reduced anisotropy in patients with schizophrenia in frontal white matter $[28,29,57,58]$, the cingulum bundle $[31,59]$, the temporal gyrus $[32,60]$, and the corpus callosum $[32,34,61]$.

Given that MRS and DTI can provide complementary imaging data on white matter changes in brain we sought to investigate the white matter brain changes associated with schizophrenia by simultaneously acquiring DTI and MRS data in a cohort of schizophrenic patients and a group of matched healthy control subjects. MRS was acquired targeting three regions of interests: frontal white matter, occipital white matter and medial temporal white matter. Since the DTI scans are much less time-consuming than MRS scans, we acquired whole brain DTI and extracted matching voxels for correlation analysis with the MRS voxels.

\section{Methods \\ Subjects}

Schizophrenic subjects were recruited from inpatient, outpatient, day treatment and vocational rehabilitation services at Mount Sinai Hospital (New York, N.Y.), Pilgrim Psychiatric Center (W. Brentwood, N.Y.), Bronx VA Medical Center (Bronx, N.Y.), Hudson Valley Veterans Affairs Medical Center (Montrose, N.Y.), and Queens Hospital Center (Jamaica, N.Y.) following approvals by each institutional review board. Informed consent was obtained on each subject following an assessment of capacity to provide informed consent by a psychiatrist independent of the study. The inclusion criteria were 1) a DSMIV diagnosis of schizophrenia or schizoaffective disorder based on the Comprehensive Assessment of Symptoms And History (CASH) [62], and 2) aged 18-80. Healthy comparison subjects who were without any DSMIV axis I disorder (by CASH interview) were recruited from the New York area and were matched for age and gender to the schizophrenic subjects, they also provided informed consent. Subjects were excluded if they had 1) a positive urine drugs of abuse screen, 2) a medical diagnosis which may 
produce white matter changes (i.e. HIV, MS), 3) a history of brain disorder which may produce cognitive impairment or behavioral symptoms (i.e. head injury, cerebrovascular disease), or 4) had an unstable medical condition (i.e. poorly controlled diabetes or hypertension, symptomatic coronary artery disease). Each subject was carefully screened and evaluated with a neuropsychological evaluation, structured assessment of symptoms, screening medical history, physical examination and laboratory studies (including complete blood count, routine chemistry, liver enzymes, and thyroid function tests) and urine toxicology screen, to ensure they fulfilled the inclusion criteria.

42 schizophrenic subjects and 40 healthy comparison subjects were recruited, assessed and scanned with both DTI and MRS modalities. Mean age of the schizophrenic group did not differ significantly from the healthy comparison group (schizophrenic mean $=38.69$ years $[\mathrm{sd}=$ $11.42]$ ), healthy comparison mean $=43.3$ years $[\mathrm{sd}=$ $20.18], t=1.28, p=.20$ ), nor did the gender distribution (healthy comparison males $=57.5 \%$, schizophrenic males $\left.=69 \%, \mathrm{X}^{2}=1.18, \mathrm{p}=.28\right)$. However, schizophrenic subjects attained significantly lower levels of education than the healthy comparison subjects (schizophrenic mean = 12.21 years $[\mathrm{sd}=2.07])$, healthy comparison mean $=15.3$ years [ $\mathrm{sd}=2.24], \mathrm{t}=6.48, \mathrm{p}<.001$ ). The average age of illness onset for the schizophrenic group was 23.53 years (sd $=7.09$ ), $5 \%$ of the schizophrenic sample was not receiving treatment with any antipsychotic at the time of scanning while $19 \%$ were receiving first generation antipsychotics, $17 \%$ clozapine, and 59\% were receiving other second generation antipsychotics (risperidone, olanzapine, ziprasidone, quetiapine, aipiprazole).

\section{Data Acquisition}

All imaging studies were performed on an Allegra 3T head-dedicated system (Siemens, Ehrlangen, Germany) with a gradient strength of $40 \mathrm{mT} / \mathrm{m}$ and slew rate of 400 900 mT/m/s, allowing EPI acquisitions with minimal susceptibility distortions. Patient head motion was minimized by inflatable pillows inserted between the patients' head and the head coil. Subjects were recruited to receive two scans, one MRS and one structural. Most subjects received both scans on the same day, but there were some that preferred to return on a second day for the other scan. The duration between the two scans was at most 2 months apart. During this time there was no change in treatment that the patients received.

\section{MRS}

Localizer MR images for prescribing the MRS volumes consisted of a T1 sagittal with the following parameters: $\mathrm{TR}=500 \mathrm{~ms}, \mathrm{TE}=10 \mathrm{~ms}, \mathrm{FOV}=18 \mathrm{~cm} \times 14 \mathrm{~cm}$, matrix size $=512 \times 384,4.3 \mathrm{~mm}$ thick with $1.1 \mathrm{~mm}$ spacing. 25 slices were obtained to cover the whole brain. From these sagittal images, two T1-weighted transverse slices $(\mathrm{TR}=$
$500 \mathrm{~ms}, \mathrm{TE}=10 \mathrm{~ms}$, Thickness $=10 \mathrm{~mm}, \mathrm{FOV}=16.5 \mathrm{~cm}$ $\times 22 \mathrm{~cm}$ with matrix $512 \times 384$ ) were identified for MRS acquisition: the first slice covered the DLPFC white matter and the OC white matter. A nearly axial plane was chosen for the plane going through the striatum. It is chosen to be parallel to the AC-PC line as identified on the sagittal planes (Fig 1). The second slice was prescribed to be coaxial with the Sylvian fissure such that it contained the medial temporal lobe white matter bilaterally (Fig 2). 1H spectroscopic imaging (SI) data of the left and right medial temporal lobes were obtained in two sequential scans using the phase-encoded version of the standard PRESS volume localization sequence, with $\mathrm{TR}=2000 \mathrm{~ms}$, $\mathrm{TE}=30 \mathrm{~ms}, 24 \times 24$ phase-encoding steps over a field-ofview of $16 \mathrm{~cm}$ (zerofilled to $32 \times 32$ phase-encoding steps before 3D Fourier transformation), a slice thickness of 10 $\mathrm{cm}$ slice, 1 average per phase-encoding step and circular kspace sampling, to obtain voxels having a nominal size of $0.25 \mathrm{~cm} 3\left(1.0 \times 0.5 \times 0.5 \mathrm{~cm}^{3}\right)$. Outer volume saturation bands were prescribed to coincide with all 8 sides of the PRESS box. Water suppression and magnet shimming were automatically performed and adjusted by the host computer. The $1 \mathrm{H}$ SI data for the DLPFC were acquired with the same protocol except that the FOV changed to 30 $\mathrm{cm}$. The resulting interpolated pixel size was $(1.0 \times 0.9 \times$ $\left.09 \mathrm{~cm}^{3}\right)$. One slice was acquired for the DLPFC and OC white matter tracts. Total imaging time for all three slices averaged about 75 minutes.

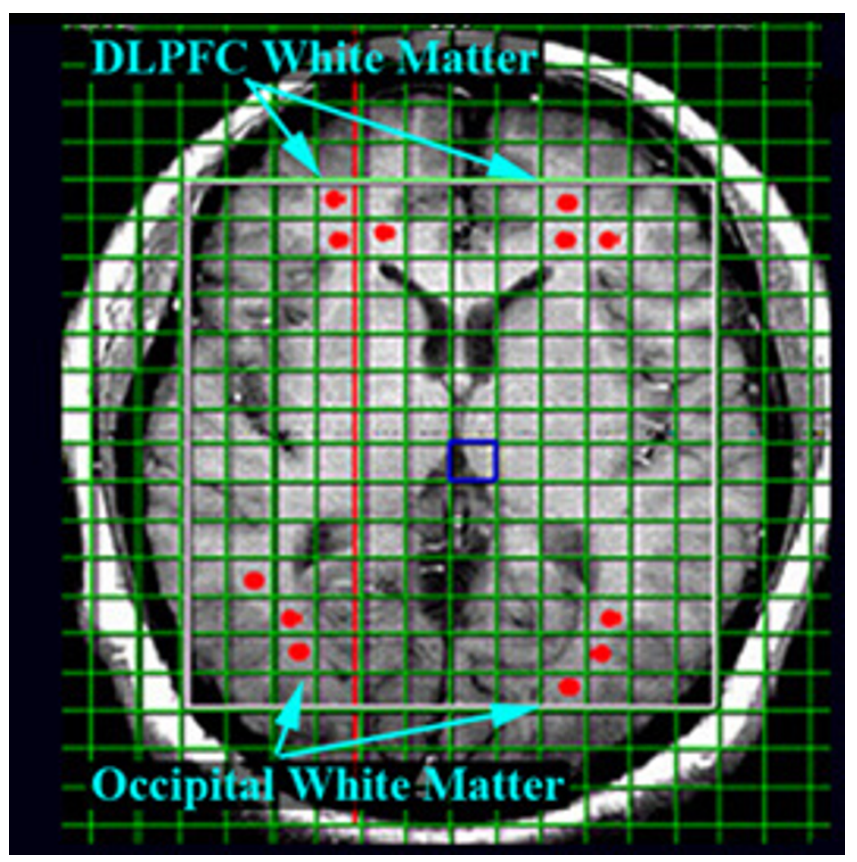

Figure I

TI-weighted axial slice for DLPF wm and OCC wm regions with CSI acquisition matrix and ROls for metabolites quantification superimposed. 


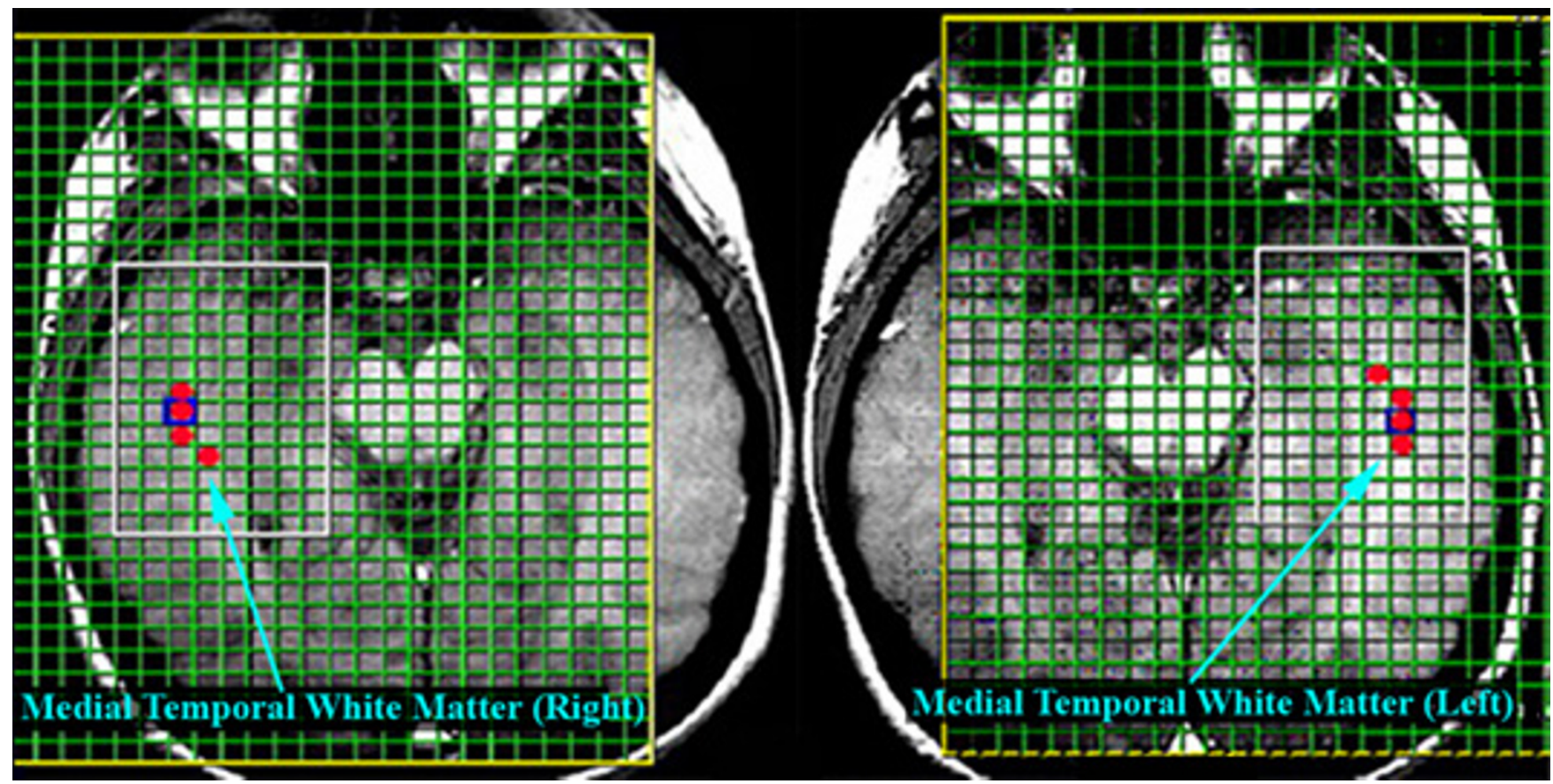

Figure 2

TI-weighted axial slices for left and right MT wm regions with CSI acquisition matrix superimposed as well as ROIs for metabolites quantification.

The raw SI data were processed and fitted in the frequency-domain to obtain metabolite peak areas using manufacturer-supplied MRS data processing software. Individual CSI images were reconstructed and overlaid onto the T1 anatomical images. Automatic phase correction was applied, voxels of interests were identified, and the metabolite levels were derived from the spectral fits. For the DLPFC white matter and OC white matter ROIs, three voxels were identified visually (Fig 1 ) for each hemisphere. For the MT white matter four voxels were identified per hemisphere because of the higher CSI resolution (Fig 2). MRS metabolites (NAA, Cho, Cr, Ins1 \& Ins2) were obtained from these regions of interests (ROIs) (Fig 3 ). The number of voxels per ROI was variable ranging between 1 and 3. Voxels with poor spectral data quality, defined asunresolved $\mathrm{Cr}$ and Cho resonances, were excluded from analysis. The metabolites from the selected voxels in each of the ROIs were averaged and transferred to Statistica v6 (StatSoft Inc., Tulsa, Ok) for statistical analysis.

DTI

DTI data was acquired in a separate scanning session that included other structural scans for morphological analysis. The protocol for the structural scans consisted of a three-plane sagittal localizer from which all other structural scans were prescribed. The following structural scans were acquired: Axial 3D-MPRage $(\mathrm{TR}=2500 \mathrm{~ms}$, $\mathrm{TE}=4.4$ $\mathrm{ms}, \mathrm{FOV}=21 \mathrm{~cm}$, matrix size $=256 \times 256,208$ slices with thickness $=0.82 \mathrm{~mm}$ ); Turbo spin echo T2-weighted Axial $(\mathrm{TR}=5380 \mathrm{~ms}, \mathrm{TE}=99 \mathrm{~ms}, \mathrm{FOV}=18.3 \mathrm{~cm} \times 21 \mathrm{~cm}$, matrix $=512 \times 448$, Turbo factor $=11,28$ slices, thickness $=3 \mathrm{~mm}$ skip $1 \mathrm{~mm}$ ); DTI using a pulsed-gradient spinecho sequence with EPI-acquisition $(\mathrm{TR}=4100 \mathrm{~ms}$, $\mathrm{TE}=$ $80 \mathrm{~ms}, \mathrm{FOV}=21 \mathrm{~cm}$, matrix $=128 \times 128,28$ slices, thickness $=3 \mathrm{~mm}$ skip $1 \mathrm{~mm}$, b-factor $=1250 \mathrm{~s} / \mathrm{mm}^{2}, 12$ gradient directions, 5 averages); and magnetization transfer imaging (MTI) using a turbo spin echo sequence $(\mathrm{TR}=$ $700 \mathrm{~ms}, \mathrm{TE}=12 \mathrm{~ms}, \mathrm{FOV}=21 \mathrm{~cm}$, Matrix $=256 \times 256,28$ slices, thickness $=3 \mathrm{~mm}$ skip $1 \mathrm{~mm}$ ). Total imaging time for the structural scans averaged about 50 minutes.

Raw DTI data were transferred to an off-line workstation for post-processing. In-house software written in Matlab v6.5 (The Mathworks Inc. Natick, MA) was used to compute the anisotropy and vector maps. The Fractional Anisotropy images were then converted to analyze format (Fig 4). MEDx v3.4.3 software (Medical Numerics Inc, Sterling, VA) was used to inspect and define ROIs on the FA images. Two adjacent axial slices $(4 \mathrm{~mm})$ were selected from the FA dataset for each matching CSI image (10 $\mathrm{mm}$ ). The planes were selected to contain the same CSI voxel locations (Fig 5). The voxels for the FA images measured $1.6 \times 1.6 \times 3 \mathrm{~mm}^{3}$. ROI dimensions for the FA images were set to $5 \times 5$ and $3 \times 3$ for the DLPFC/OC and MT respectively. These settings gave us the closest match to the 

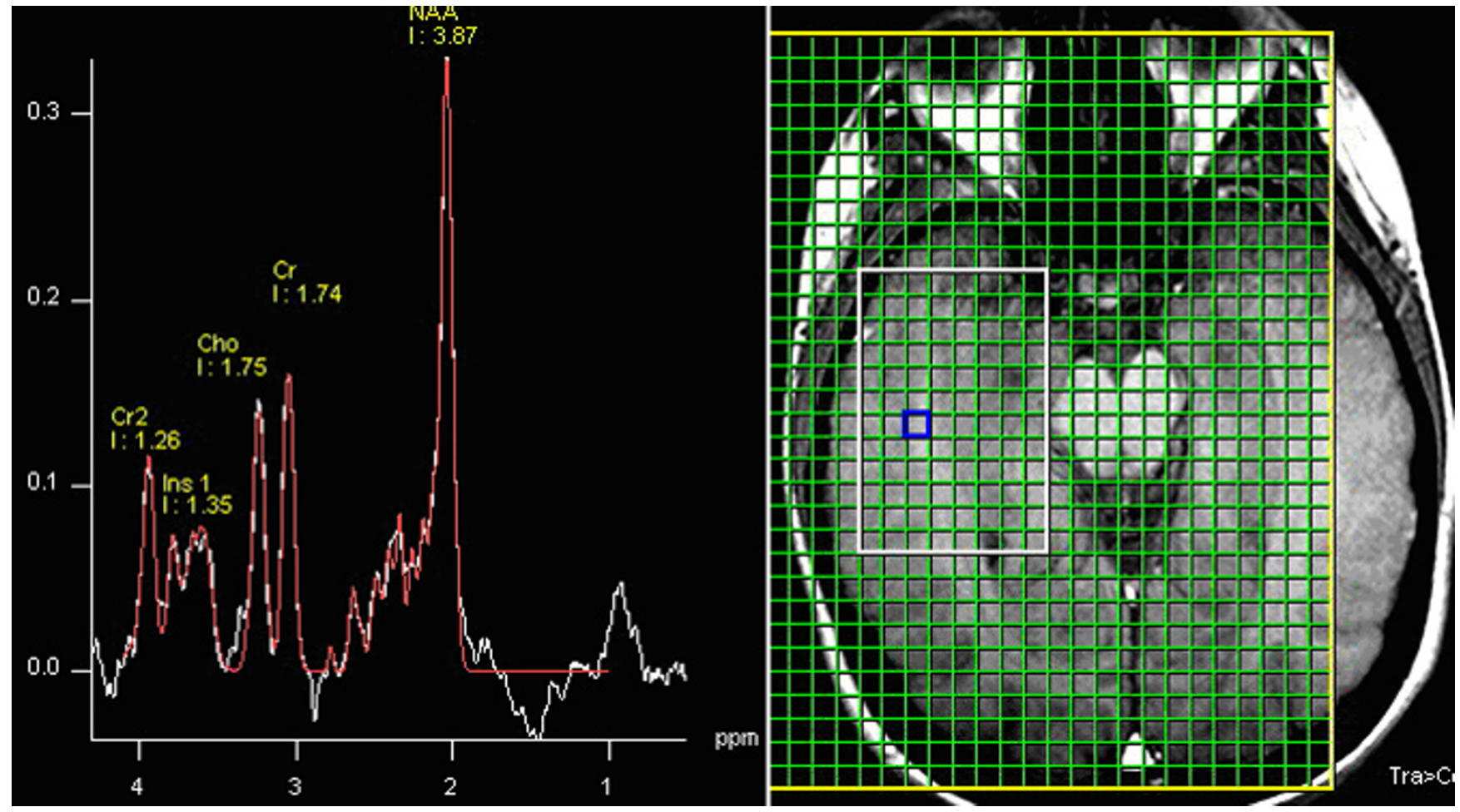

Figure 3

Example of MRS spectrum of a MT wm voxel (blue square) extracted from a 2D-CSI acquisition. Visible metabolite peaks shown are NAA, Cr, Cho, InsI and Ins2.

MRSI data in terms of actual volumes sampled; ROI dimensions for DLPFC and OC were $8.2 \mathrm{~mm}$ (FA) vs. 9 $\mathrm{mm}$ (MRSI), ROI dimensions for the MT were $4.9 \mathrm{~mm}$ (FA) vs. $5 \mathrm{~mm}$ (MRSI). For all structures 2 FA slices were sampled corresponding to a thickness of $8 \mathrm{~mm}$ (FA) vs. 10 $\mathrm{mm}$ (MRSI). The FA voxel statistics for each ROI were extracted and transferred to Statistica and merged with MRS data for $\mathrm{t}$-tests and correlation analysis.

In order to ensure reliability of our region of interest procedures inter-rater reliability measures were calculated for the two raters for each white matter region in 20 subjects. The intraclass correlation coefficients on the mean values of the ROIs as obtained by the two raters were as follows; optic radiations $($ right $=.83$, left $=.83), \mathrm{MT}($ right $=.88$, left $=.91)$, DLPF WM (right $=.94$, left $=.84)$.

\section{Results}

Statistical tests between the average ROI values were performed on the fractional anisotropy as well as the MRSI data for the three regions of interests in both hemispheres. Table 1 shows the mean fractional anisotropy and metabolite ratio values for the schizophrenic and healthy comparison groups in each medial temporal regions of interest. Independent $\mathrm{T}$-tests on the metabolite ratios demonstrated significantly reduced NAA in the left medial temporal white matter regions in patients with schizophrenic subjects (mean $=1.17)$ compared to healthy control subjects $($ mean $=1.31)(\mathrm{t}=2.35, \mathrm{df}=75, \mathrm{p}<.021)$. Similar significances were found in the right medial temporal white matter regions with schizophrenic subjects $($ mean $=1.07)$ and healthy control subjects $($ mean $=1.21)$ $(\mathrm{t}=2.29, \mathrm{df}=75, \mathrm{p}<.025)$. We also computed the significances for NAA/Cr ratios in the medial temporal white matter region. Significant differences were found in the left with schizophrenic subjects (mean $=1.96$ ) and healthy controls $($ mean $=2.37)(\mathrm{t}=2.58, \mathrm{df}=75, \mathrm{p}<$ 0.012 ) as well as on the right with schizophrenic subjects $($ mean $=1.94)$ and healthy controls $($ mean $=2.25)(\mathrm{t}=$ $2.17, \mathrm{df}=75, \mathrm{p}<0.033$ ). Other areas and metabolite concentrations were not significantly different between groups.

T-tests on the matching voxels of the FA data showed significantly reduced FA values in the same right medial temporal white matter voxels as the MRS in patients with schizophrenia compared to normal control subjects $(0.307$ vs. 0.342$)(t=3.02, d f=79, p<.003)$. FA was also significantly reduced in the left medial temporal white matter region of schizophrenic subjects compared to healthy control subjects $(0.339$ vs. 0.370$)(\mathrm{t}=2.31, \mathrm{df}=$ $79, \mathrm{p}<.023)$. Other areas surveyed were not significant. 

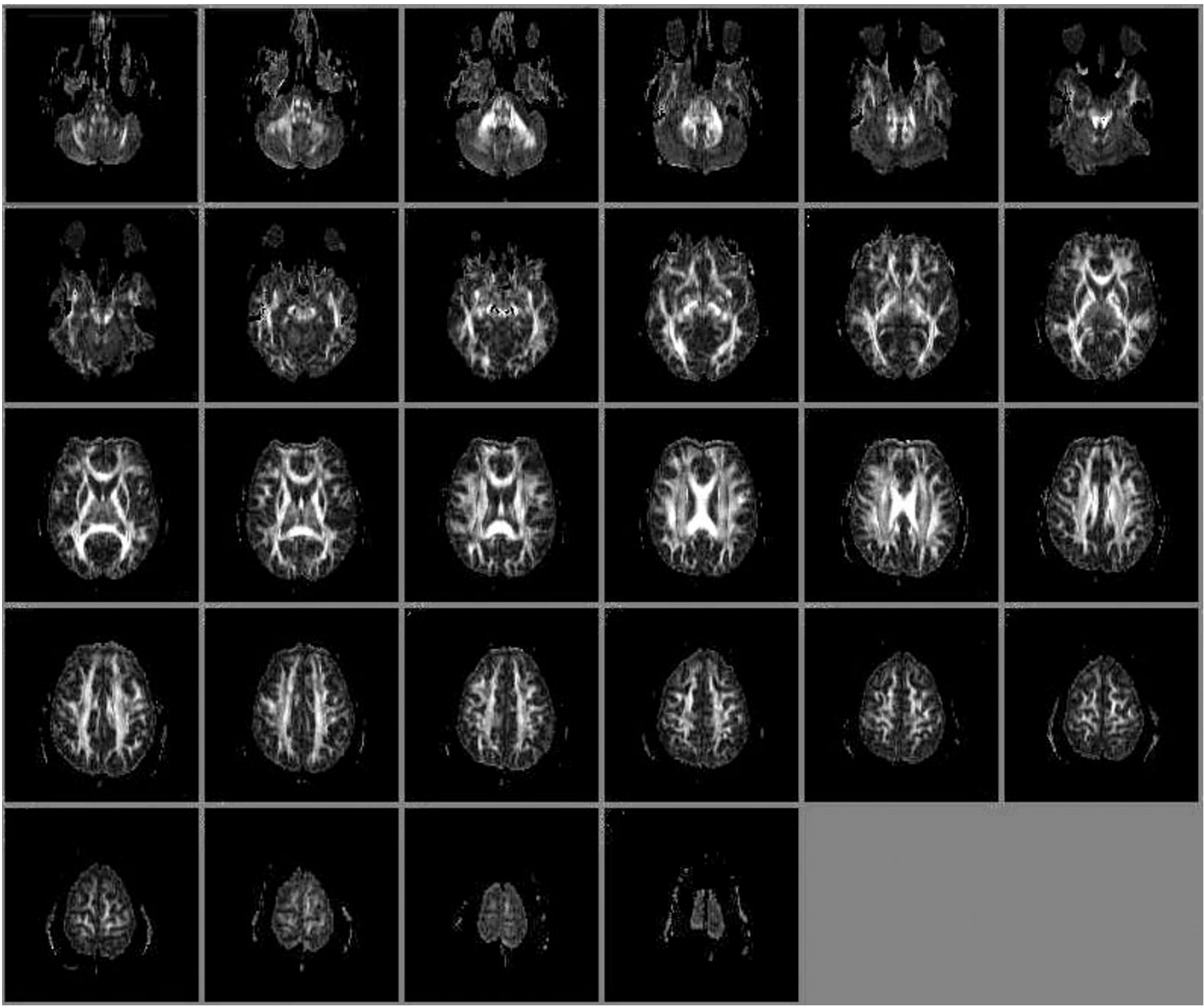

Figure 4

Diffusion Tensor Imaging: Whole-Brain Fractional Anisotropy Maps of normal control.

Correlation analysis on combined patient and control subjects showed a significant correlation between FA and NAA in the left medial temporal $(\mathrm{r}=0.210, \mathrm{p}=.050)$ as well as FA and NAA/Cr $(r=0.230, p=0.040)$. No significant correlation was found in the right medial temporal side $(\mathrm{r}=0.210, \mathrm{p}=0.090)$ and $(\mathrm{r}=0.140, \mathrm{p}=0.220)$. There have been several reports suggesting that additional neuro-degenerative factors such as age might have effects on FA $[63,64]$. NAA in our patient sample as well as some other studies [65] did not show any age effect. We have also tested partial correlations with the FA values corrected for age: a slight increase in significances were found in the same regions, correlations between FA and NAA, $\mathrm{NAA} / \mathrm{Cr}$ in the left medial temporal white matter were ( $\mathrm{r}$
$=0.332 ., \mathrm{p}=.010)$ and $(\mathrm{r}=0.308, \mathrm{p}=0.017)$ respectively. The correlations in all other ROIs surveyed were not significant: right medial temporal side $(\mathrm{r}=0.20, \mathrm{p}=0.07)$ and $(\mathrm{r}=0.16, \mathrm{p}=0.22)$; left DLPFC $(\mathrm{r}=0.03, \mathrm{p}=0.80)$ and $(\mathrm{r}=-0.07, \mathrm{p}=0.56)$, right DLPFC $(\mathrm{r}=0.07, \mathrm{p}=0.56)$ and $(\mathrm{r}=0.23, \mathrm{p}=0.06)$, left occipital $(\mathrm{r}=0.13, \mathrm{p}=0.10)$ and $(r=0.15, p=0.21)$, right occipital $(r=0.10, p=0.39)$ and $(r=0.18, p=0.13)$ respectively.

\section{Discussion}

The regions sampled in the current study shows that NAA/ $\mathrm{Cr}$ and fractional anisotropy are reduced in the medial temporal white matter in patients with schizophrenia. Reduced anisotropy was detected in the areas surveyed 
Table I: Mean values of metabolite ratios and fractional anisotropy (FA) and for the Medial Temporal, DLPFC and Occipital white matter ROls. Significant differences between schizophrenic and healthy control subject groups by independent $t$ tests are highlighted in bold.

\begin{tabular}{|c|c|c|c|c|c|c|c|c|c|}
\hline \multicolumn{4}{|c|}{ NAA } & \multicolumn{2}{|c|}{ NAA/Cr } & \multicolumn{4}{|c|}{ FA } \\
\hline ROI & $\begin{array}{l}\text { Schizophrenic } \\
\text { Mean (SD) }\end{array}$ & $\begin{array}{l}\text { Control } \\
\text { Mean (SD) }\end{array}$ & $\mathbf{p}$ & $\begin{array}{l}\text { Schizophrenic } \\
\text { Mean (SD) }\end{array}$ & $\begin{array}{l}\text { Control } \\
\text { Mean (SD) }\end{array}$ & $\mathbf{p}$ & $\begin{array}{l}\text { Schizophrenic } \\
\text { Mean (SD) }\end{array}$ & $\begin{array}{l}\text { Control } \\
\text { Mean (SD) }\end{array}$ & $\mathbf{p}$ \\
\hline $\begin{array}{l}\text { R Medial } \\
\text { Temporal }\end{array}$ & $1.076(0.233)$ & $1.210(0.276)$ & $<0.025$ & $1.937(0.556)$ & $2.254(0.716)$ & $<0.033$ & $0.307(0.052)$ & $0.342(0.073)$ & $<0.003$ \\
\hline $\begin{array}{l}\text { L Medial } \\
\text { Temporal }\end{array}$ & $1.171(0.273)$ & $1.308(0.238)$ & $<0.021$ & $1.956(0.732)$ & $2.368(0.732)$ & $<0.012$ & $0.370(0.082)$ & $0.339(0.064)$ & $<0.023$ \\
\hline R Frontal & $4.260(1.420)$ & $3.970(1.230)$ & $P=0.38$ & $2.290(0.770)$ & $1.990(0.610)$ & $P=0.08$ & $0.230(0.043)$ & $0.244(0.055)$ & $P=0.21$ \\
\hline L Frontal & $4.550(1.440)$ & $4.450(1.330)$ & $p=0.77$ & $2.320(0.730)$ & $2.280(1.080)$ & $p=0.88$ & $0.226(0.044)$ & $0.237(0.052)$ & $p=0.30$ \\
\hline R Occipital & $4.050(2.240)$ & $4.070(1.320)$ & $p=0.96$ & $3.870(2.540)$ & $2.360(0.780)$ & $p=0.30$ & $0.315(0.045)$ & $0.325(0.05 I)$ & $p=0.36$ \\
\hline L Occipital & $4.360(2.640)$ & $4.270(1.520)$ & $p=0.87$ & $2.840(1.830)$ & $2.520(0.730)$ & $p=0.34$ & $0.356(0.069)$ & $0.364(0.059)$ & $p=0.60$ \\
\hline
\end{tabular}

despite normal appearing white matter on conventional T1 and T2 weighted images which suggest microscopic damage to these fiber tracts.

NAA is thought to be present almost exclusively in neurons and their dendritic and axonal extensions but not in glia [66-68]. The NAA signal provides a marker of the number of viable neurons [69]. NAA is an intracellular amino acid derivative produced in the mitochondria [70], but it is also found in large quantities in $\mathrm{O}-2 \mathrm{~A}$ progenitor cells [35]. O2-A progenitor cells are putatively involved with glia repair processes[71]. MS studies have shown that it is the failure of these repair processes that is the main cause of the disease [72]. A reduction in NAA may reflect both a volume loss as well as a defect in the myelin maintenance infrastructure. FA indices from DTI measurements reflect the amount of coherently restricted diffusion (imposed by the presence of myelin) of free

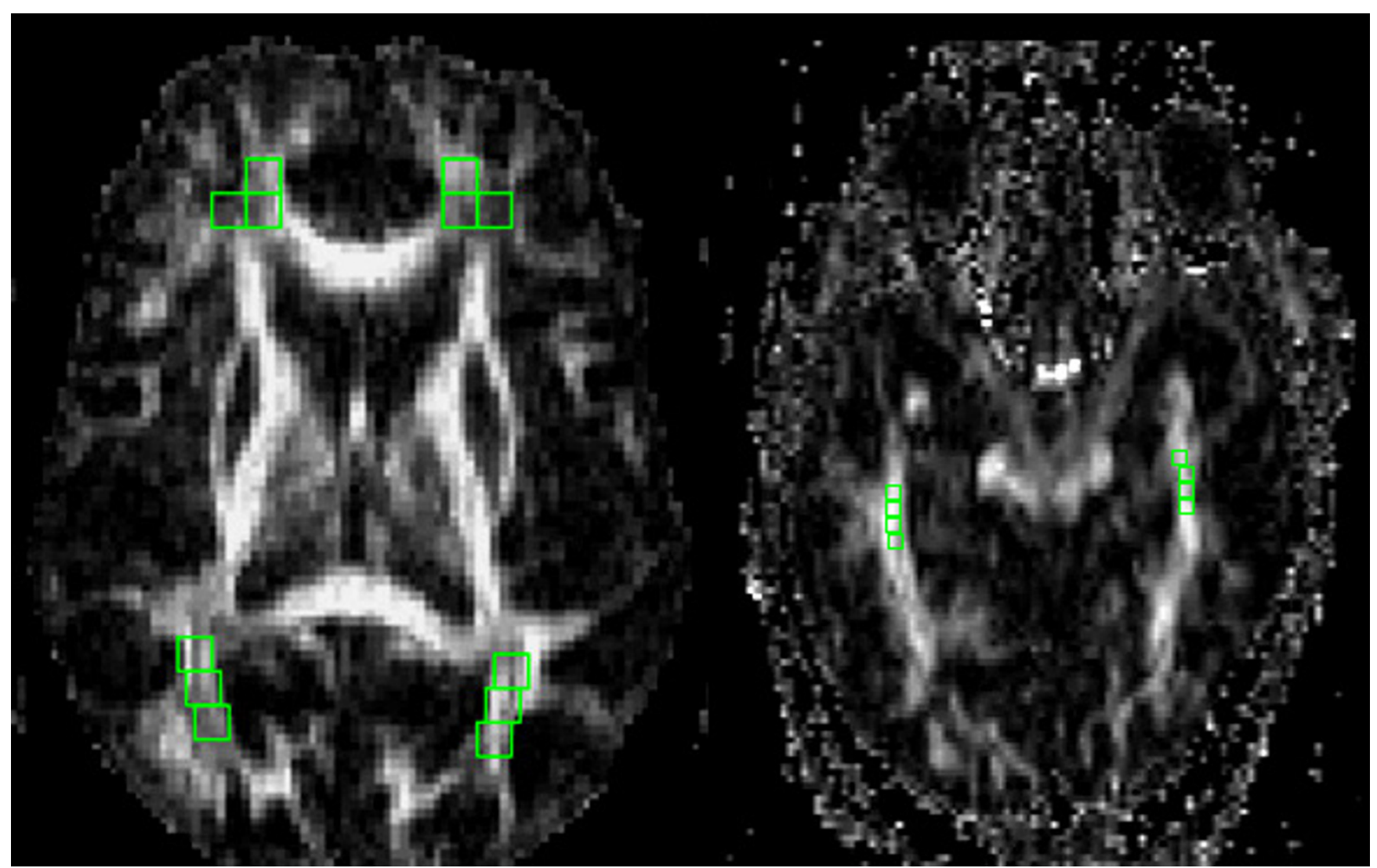

Figure 5

ROI locations (left) DLPF wm, OCC wm and (right) MT wm for Fractional Anisotropy Data. 
water. These coherently restricted diffusion pathways are most prominent in axonal bundles. DTI voxels are several orders of magnitude larger than cellular dimensions, so that the computed anisotropy indices reflect the cumulative effect of the underlying microstructure. While there is still controversy regarding the source of the anisotropy such as the contribution of the intracellular versus extracellular water to the diffusion signal [73-76], one can argue from a physical point of view that a reduced anisotropy can be the result of one of the following phenomenon: loss of myelin leading to reduced restricted diffusion, intact fibers but not coherently oriented and loss of fibers. Measurements using multiple b-values have shown a dependence of the diffusion signal on fast and slow diffusion as well as a deviation from mono-exponential signal decay with higher b-values. With b-values below $2000 \mathrm{~s} / \mathrm{mm}^{2}$ the signal decays mono-exponentially and is most sensitive to fast diffusion [74]. Our DTI data was acquired with a b-value of $1250 \mathrm{~s} / \mathrm{mm}^{2}$ and is thus sensitized to fast diffusing water protons (probably in the extra-cellular

space).

In a systematic review of proton MRS investigations measuring NAA differences between healthy controls and patients with schizophrenia [77] levels of NAA do appear to be substantially reduced in frontal WM and temporal WM of schizophrenic patients. Although studies of temporal WM NAA changes are less well corroborated than frontal WM changes in schizophrenia the mean reduction of FA in temporal WM across studies was estimated at $12.7 \%$ compared to $5.2 \%$ for frontal WM [77]. Moreover, antipsychotic treatment of the patients in our study may have confounded the measurements of NAA in the prefrontal white matter. In a longitudinal evaluation chronic schizophrenic patients first scanned off medication then after treatment was started NAA levels increased significantly and selectively in the dorsolateral prefrontal cortex within 4 weeks but not in temporal lobe or other areas assessed [42]. The fact that we only found significant differences in the medial temporal white matter may support these findings.

Our group has previously published a report on the DTI findings of the same subject population [78]. SPM analysis showed that there were significant differences in the medial temporal white matter as well as frontal white matter regions. The areas of significance were in the same locations as our ROI placements. The reason that we did not find significant FA differences in the frontal white matter is partly due to the size of the ROIs. The ROI dimensions and locations chosen for the current analysis was based on the need to match the voxels obtained from the MRS data. These results suggest that axonal disruptions in the frontal white matter areas might be limited to specific tracts within the frontal white matter. The subjects used for the current analysis is a subset of the subjects used in our previous report $(\mathrm{N}=55, \mathrm{~S}=63$ ) versus (N42, $\mathrm{S}=40$ ) because some scans had to be eliminated due to poorly resolved spectra.

A similar study was performed by Steel et. al. [79], but no significant differences were found in NAA or FA. This might have been due to several reasons. Single voxel MRS is prone to partial volume contamination. Our technique used multivoxel spectroscopic imaging with much smaller voxel size; we only sampled the voxels which are well contained within the white matter regions. The second reason for the difference in findings may be due to our much larger sample of subjects $(\mathrm{n}=40 / 42$ vs. $\mathrm{n}=10 / 10)$ and potential mean age differences (Steel's group $=35 / 34$, this study $=43 / 39)$. The Steel's group did not survey the medial temporal lobe which was the location where we found significances for both NAA and FA.

A more recent study has been performed by Irwan et. al. [80] using DTI and CSI acquired in a supraventricular slice in normal control subjects. Although they have not specifically looked at isolated white matter voxels, they have shown a significant positive correlation between NAA and FA as well as a significant negative correlation between NAA with ADC values which is consistent with our interpretation of the FA index.

We also found significant correlations between FA and NAA in the left medial temporal white matter. Despite the co-occurrence of the reductions in NAA and fractional anisotropy these values were not significantly correlated on the right side ( $\mathrm{p}=0.07)$. These relatively weak significances were only observed when correlations were computed with both control subjects and patients combined. Therefore, these results between these two measures in the same region may be suggestive of different structural and/or metabolic changes co-occurring in the same region, but independent of each other, in contrast to what is observed in multiple sclerosis [81]. For example, patients with schizophrenia may be born with proper axonal formation but defective myelin maintenance infrastructure as reflected by reduced NAA/Cr. This interpretation is reasonable given that NAA is also found in large quantities in $\mathrm{O}-2 \mathrm{~A}$ progenitor cells [35] putatively involved with glia repair processes [71]. In this scenario our results could be interpreted such that the reduction of anisotropy in this area might occur gradually whereas the low NAA/Cr levels could be constant throughout the lifespan of the patients. Low NAA may be a hallmark throughout the lifespan of the disease but its effect and other factors on FA may be more gradual.

One limitation of this study lies in the coregistration of the MRS ROIs with the DTI ROIs. Due to the lower sensi- 
tivity of MRS, the acquisition of MRS data is inherently slower and the resulting data is of lower resolution. We were only able to acquire two slices of MRS data. This made it impossible to accurately coregister the MRS slices to the DTI slices using conventional computer algorithms. The problem is compounded by the inherent distortions that exists in EPI based DTI acquisition schemes. In this study we have relied on our anatomy experts to visually identify the regions of interests. To minimize the error we have acquired the MRS slice for the DLPFC and the occipital regions in the same plane as the DTI which was along the AC-PC plane. This made it easier to identify the same regions on both modalities. Other limitations are the differences in slice thickness between the two modalities. The MRS was $10 \mathrm{~mm}$ thick whereas the DTI were $3 \mathrm{~mm}$ skip $1 \mathrm{~mm}$. To minimize this difference we selected two DTI slices for every MRS slice.

\section{Conclusion}

Our study has provided further evidence of white matter abnormality in the medial temporal region in chronic schizophrenic patients. This was evidenced through MR Spectroscopy as well as Diffusion Tensor Imaging. Applying these two imaging modalities to an at risk population at a younger age before the disease is diagnosed and correlating the results with outcome would elucidate the sequence of events such as defective NAA preceding reduced FA. Differences in the MRS and DTI results may help one distinguish the nature of the white matter defects.

\section{Competing interests}

The author(s) declare that they have no competing interests.

\section{Authors' contributions}

CYT was responsible for the DTI software development, MRI protocols, analysis and interpretation of the results. JF and DS was responsible for the recruitment and screening of the subjects. LC, TE and DS were responsible for the MRS protocols. AH, DC, JN and XM were responsible for ROI tracings. PRH was responsible for the anatomical localization of the ROIs.

The study was conceived by KD, MSB and JMG. All authors have read and approved the final manuscript.

\section{Acknowledgements}

This work was supported by the following grants:

I. P50 MH 66392-0I awarded by the NIMH to Kenneth Davis.

\section{VISN3 MIRECC.}

3. GCRC grant M0I-RR-0007I awarded to Mount Sinai School of Medicine.

\section{References}

I. Benes FM: Emerging principles of altered neural circuitry in schizophrenia. Brain Res Brain Res Rev 2000, 31:25I-269.

2. Bunney WE, Bunney BG: Evidence for a compromised dorsolateral prefrontal cortical parallel circuit in schizophrenia. Brain Res Brain Res Rev 2000, 31: I38-146.

3. Carlsson A, Waters N, Holm-Waters S, Tedroff J, Nilsson M, Carlsson ML: Interactions between monoamines, glutamate, and GABA in schizophrenia: new evidence. Annu Rev Pharmacol Toxicol 200I, 4I:237-260.

4. Grace AA: Gating of information flow within the limbic system and the pathophysiology of schizophrenia. Brain Res Brain Res Rev 2000, 31:330-341.

5. Heimer L: Basal forebrain in the context of schizophrenia. Brain Res Brain Res Rev 2000, 3 I:205-235.

6. Middleton FA, Strick PL: Basal ganglia and cerebellar loops: motor and cognitive circuits. Brain Res Brain Res Rev 2000, 3I:236-250.

7. Selemon LD, Rajkowska G, Goldman-Rakic PS: Elevated neuronal density in prefrontal area 46 in brains from schizophrenic patients: application of a three-dimensional, stereologic counting method. J Comp Neurol 1998, 392:402-4I2.

8. Selemon LD, Rajkowska G, Goldman-Rakic PS: Abnormally high neuronal density in the schizophrenic cortex. A morphometric analysis of prefrontal area 9 and occipital area 17. Arch Gen Psychiatry 1995, 52:805-18; discussion 819-20.

9. Pakkenberg B: Total nerve cell number in neocortex in chronic schizophrenics and controls estimated using optical disectors. Biol Psychiatry 1993, 34:768-772.

10. Williams RW, Rakic P: Elimination of neurons from the rhesus monkey's lateral geniculate nucleus during development. J Comp Neurol 1988, 272:424-436.

II. Selemon LD, Goldman-Rakic PS: The reduced neuropil hypothesis: a circuit based model of schizophrenia. Biol Psychiatry 1999, 45: 17-25.

12. Davis SR, Lewis DA: Local circuit neurons of the prefrontal cortex in schizophrenia: selective increase in the density of calbindin-immunoreactive neurons. Psychiatry Res 1995, 59:8I-96.

13. Akbarian S, Kim JJ, Potkin SG, Hetrick WP, Bunney WE Jr., Jones EG: Maldistribution of interstitial neurons in prefrontal white matter of the brains of schizophrenic patients. Arch Gen Psychiatry 1996, 53:425-436.

14. Wright IC, Rabe-Hesketh S, Woodruff PW, David AS, Murray RM, Bullmore ET: Meta-analysis of regional brain volumes in schizophrenia. Am J Psychiatry 2000, 157:16-25.

15. Cannon TD, van Erp TG, Huttunen M, Lonnqvist J, Salonen O, Valanne L, Poutanen VP, Standertskjold-Nordenstam CG, Gur RE, Yan $M$ : Regional gray matter, white matter, and cerebrospinal fluid distributions in schizophrenic patients, their siblings, and controls. Arch Gen Psychiatry 1998, 55: 1084-1091.

16. Foong J, Maier M, Barker G], Brocklehurst S, Miller DH, Ron MA: In vivo investigation of white matter pathology in schizophrenia with magnetisation transfer imaging. J Neurol Neurosurg Psychiatry 2000, 68:70-74.

17. Breier A, Buchanan RW, Elkashef A, Munson RC, Kirkpatrick B, Gellad F: Brain morphology and schizophrenia. A magnetic resonance imaging study of limbic, prefrontal cortex, and caudate structures. Arch Gen Psychiatry 1992, 49:921-926.

18. Sigmundsson T, Suckling J, Maier M, Williams S, Bullmore E, Greenwood K, Fukuda R, Ron M, Toone B: Structural abnormalities in frontal, temporal, and limbic regions and interconnecting white matter tracts in schizophrenic patients with prominent negative symptoms. Am J Psychiatry 200I, I 58:234-243.

19. Buchanan RW, Vladar K, Barta PE, Pearlson GD: Structural evaluation of the prefrontal cortex in schizophrenia. Am J Psychiatry 1998, 155:1049-1055.

20. Sanfilipo M, Lafargue $T$, Rusinek $H$, Arena L, Loneragan $C$, Lautin A, Feiner D, Rotrosen J, Wolkin A: Volumetric measure of the frontal and temporal lobe regions in schizophrenia: relationship to negative symptoms. Arch Gen Psychiatry 2000, 57:47I-480.

21. Foong J, Symms MR, Barker G], Maier M, Woermann FG, Miller DH, Ron MA: Neuropathological abnormalities in schizophrenia: evidence from magnetization transfer imaging. Brain 200I, I 24:882-892.

22. Maier M, Mellers J, Toone B, Trimble M, Ron MA: Schizophrenia, temporal lobe epilepsy and psychosis: an in vivo magnetic 
resonance spectroscopy and imaging study of the hippocampus/amygdala complex. Psychol Med 2000, 30:57I-58I.

23. Bertolino A, Esposito G, Callicott JH, Mattay VS, Van Horn JD, Frank JA, Berman KF, Weinberger DR: Specific relationship between prefrontal neuronal $\mathrm{N}$-acetylaspartate and activation of the working memory cortical network in schizophrenia. Am J Psychiatry 2000, 157:26-33.

24. Rowland L, Bustillo JR, Lauriello J: Proton magnetic resonance spectroscopy (H-MRS) studies of schizophrenia. Semin Clin Neuropsychiatry 200I, 6: I2I-I30.

25. Cecil KM, Lenkinski RE, Gur RE, Gur RC: Proton magnetic resonance spectroscopy in the frontal and temporal lobes of neuroleptic naive patients with schizophrenia. Neuropsychopharmacology 1999, 20: |31-140.

26. Yurgelun-Todd DA, Renshaw PF, Gruber SA, Waternaux C, Cohen $B M$ : Proton magnetic resonance spectroscopy of the temporal lobes in schizophrenics and normal controls. Schizophrenia Research 1996, 19:55-59.

27. Fukuzako H, Kodama S, Fukuzako T, Yamada K, Doi W, Sato D, Takigawa M: Subtype-associated metabolite differences in the temporal lobe in schizophrenia detected by proton magnetic resonance spectroscopy. Psychiatry Res 1999, 92:45-56.

28. Buchsbaum MS, Tang CY, Peled S, Gudbjartsson H, Lu D, Hazlett EA Downhill J, Haznedar M, Fallon J: MRI white matter diffusion anisotropy and PET metabolic rate in Schizophrenia. Neuroreport 1998, 9:425-430.

29. Lim KO, Hedehus M, Moseley M, de Crespigny A, Sullivan EV, Pfefferbaum $A$ : Compromised white matter tract integrity in schizophrenia inferred from diffusion tensor imaging. Arch Gen Psychiatry 1999, 56:367-374.

30. Kalus P, Buri C, Slotboom J, Gralla J, Remonda L, Dierks T, Strik WK, Schroth G, Kiefer C: Volumetry and diffusion tensor imaging of hippocampal subregions in schizophrenia. Neuroreport 2004, | 5:867-87|.

31. Kubicki M, Westin CF, Nestor PG, Wible CG, Frumin M, Maier SE, Kikinis R, Jolesz FA, McCarley RW, Shenton ME: Cingulate fasciculus integrity disruption in schizophrenia: a magnetic resonance diffusion tensor imaging study. Biological Psychiatry 2003, 54: $1171-1180$

32. Ardekani BA, Nierenberg J, Hoptman MJ, Javitt DC, Lim KO: MRI study of white matter diffusion anisotropy in schizophrenia. Neuroreport 2003, 1 4:2025-2029.

33. Lim KO, Helpern JA: Neuropsychiatric applications of DTI - a review. NMR Biomed 2002, 15:587-593.

34. Foong J, Maier M, Clark CA, Barker G], Miller DH, Ron MA: Neuropathological abnormalities of the corpus callosum in schizophrenia: a diffusion tensor imaging study. I Neurol Neurosurg Psychiatry 2000, 68:242-244

35. Urenjak J, Williams SR, Gadian DG, Noble M: Proton nuclear magnetic resonance spectroscopy unambiguously identifies different neural cell types. J Neurosci 1993, I3:98I-989.

36. Arnold DL, Matthews PM, Francis GS, O'Connor J, Antel JP: Proton magnetic resonance spectroscopic imaging for metabolic characterization of demyelinating plaques. Ann Neurol 1992 3I:235-24I.

37. Deicken RF, Feiwell R, Schuff N, Soher B: Evidence for altered cerebellar vermis neuronal integrity in schizophrenia. Psychiatry Res 200I, 107:125-134.

38. Auer DP, Wilke M, Grabner A, Heidenreich JO, Bronisch T, Wetter TC: Reduced NAA in the thalamus and altered membrane and glial metabolism in schizophrenic patients detected by IH-MRS and tissue segmentation. Schizophr Res 200I, 52:87-99.

39. Ende G, Braus DF, Walter S, Henn FA: Lower concentration of thalamic n-acetylaspartate in patients with schizophrenia: a replication study. Am J Psychiatry 200I, I 58:|3|4-1316.

40. Omori M, Murata T, Kimura H, Koshimoto $Y$, Kado H, Ishimori $Y$, Ito $\mathrm{H}$, Wada $\mathrm{Y}$ : Thalamic abnormalities in patients with schizophrenia revealed by proton magnetic resonance spectroscopy. Psychiatry Res 2000, 98:155-162

4I. Deicken RF, Johnson C, Eliaz Y, Schuff N: Reduced concentrations of thalamic $\mathrm{N}$-acetylaspartate in male patients with schizophrenia. Am J Psychiatry 2000, 157:644-647.

42. Bertolino A, Callicott JH, Mattay VS, Weidenhammer KM, Rakow R, Egan MF, Weinberger DR: The effect of treatment with antipsychotic drugs on brain $\mathbf{N}$-acetylaspartate measures in patients with schizophrenia. Biol Psychiatry 200I, 49:39-46.
43. Callicott JH, Bertolino A, Mattay VS, Langheim FJ, Duyn J, Coppola R, Goldberg TE, Weinberger DR: Physiological dysfunction of the dorsolateral prefrontal cortex in schizophrenia revisited. Cereb Cortex 2000, 10:1078-1092

44. Bertolino A, Breier A, Callicott JH, Adler C, Mattay VS, Shapiro M, Frank JA, Pickar D, Weinberger DR: The relationship between dorsolateral prefrontal neuronal $\mathbf{N}$-acetylaspartate and evoked release of striatal dopamine in schizophrenia. Neuropsychopharmacology 2000, 22:125-132.

45. Ende G, Braus DF, Walter S, Weber-Fahr W, Soher B, Maudsley AA, Henn FA: Effects of age, medication, and illness duration on the $\mathbf{N}$-acetyl aspartate signal of the anterior cingulate region in schizophrenia. Schizophr Res 2000, 41:389-395.

46. Szulc A, Galinska B, Tarasow E, Walecki J, Dzienis W, Kubas B, Czernikiewicz A: [Clinical and neuropsychological correlates of proton magnetic resonance spectroscopy detected metabolites in brains of first-episode and schizophrenic patients]. Psychiatr Pol 2003, 37:977-988.

47. Fukuzako H, Takeuchi K, Hokazono Y, Fukuzako T, Yamada K, Hashiguchi T, Obo Y, Ueyama K, Takigawa M, Fujimoto T: Proton magnetic resonance spectroscopy of the left medial temporal and frontal lobes in chronic schizophrenia: preliminary report. Psychiatry Res 1995, 61:193-200.

48. Bitsch A, Bruhn H, Vougioukas V, Stringaris A, Lassmann H, Frahm J, Bruck W: Inflammatory CNS Demyelination: Histopathologic Correlation with In Vivo Quantitative Proton MR Spectroscopy. AJNR Am J Neuroradiol 1999, 20:1619-1627.

49. Basser PJ: Inferring Microstructural features and the Physiological State of Tissues from Diffusion Weighted Images. NMR in Biomedicine 1995, 8:333-344.

50. Basser PJ: New histological and physiological stains derived from diffusion-tensor MR images. Ann N Y Acad Sci 1997, 820:123-138

51. Basser PJ, Pierpaoli C: Microstructural and Physiological Features of Tissues Elucidated by Quantitative-Diffusion-Tensor MRI. Journal of Magnetic Resonance, Series B 1996, I I I (3):209-2I 9 .

52. Pierpaoli C, Jezzard P, Basser PJ, Barnett A, Chiro GD: Diffusion Tensor MR Imaging of the Human Brain. Radiology 1996, 20I:637-648.

53. Pierpaoli C, Basser PJ: Toward a Quantitative Assessment of Diffusion Anisotropy. Magnetic Resonance in Medicine 1996, 36:893-906

54. Mori S, van Zijl PC: Fiber tracking: principles and strategies - a technical review. NMR Biomed 2002, I 5:468-480.

55. Bammer $R$, Acar B, Moseley ME: In vivo MR tractography using diffusion imaging. European Journal of Radiology 2003, 45:223-234.

56. Conturo TE, Lori NF, Cull TS, Akbudak E, Snyder AZ, Shimony JS, McKinstry RC, Burton H, Raichle ME: Tracking neuronal fiber pathways in the living human brain. Proc Natl Acad Sci 1999, 96: 10422-10427.

57. Wolkin A, Choi SJ, Szilagyi S, Sanfilipo M, Rotrosen JP, Lim KO: Inferior frontal white matter anisotropy and negative symptoms of schizophrenia: a diffusion tensor imaging study. Am J Psychiatry 2003, 160:572-574

58. Hoptman MJ, Volavka J, Johnson G, Weiss E, Bilder RM, Lim KO: Frontal white matter microstructure, aggression, and impulsivity in men with schizophrenia: a preliminary study. Biological Psychiatry 2002, 52:9-14.

59. Sun Z, Wang F, Cui L, Breeze J, Du X, Wang X, Cong Z, Zhang H, L $B$, Hong $N$, Zhang $D$ : Abnormal anterior cingulum in patients with schizophrenia: a diffusion tensor imaging study. Neuroreport 2003, 14:1833-1836.

60. Spalletta G, Tomaiuolo F, Marino V, Bonaviri G, Trequattrini A, Caltagirone $\mathrm{C}$ : Chronic schizophrenia as a brain misconnection syndrome: a white matter voxel-based morphometry study. Schizophrenia Research 2003, 64:15-23.

61. Agartz I, Andersson JL, Skare S: Abnormal brain white matter in schizophrenia: a diffusion tensor imaging study. Neuroreport 200I, I 2:225I-2254.

62. Andreasen NC, Flaum M, Arndt S: The Comprehensive Assessment of Symptoms and History (CASH). An instrument for assessing diagnosis and psychopathology. Arch Gen Psychiatry 1992, 49:615-623.

63. Pfefferbaum A, Sullivan EV, Hedehus M, Lim KO, Adalsteinsson E, Moseley M: Age-related decline in brain white matter anisot- 
ropy measured with spatially corrected echo-planar diffusion tensor imaging. Magn Reson Med 2000, 44:259-268.

64. Nusbaum AO, Tang CY, Buchsbaum MS, Wei TC, Atlas SW: Regional and global changes in cerebral diffusion with normal aging. AJNR Am J Neuroradiol 200I, 22:I36-I42.

65. Saunders DE, Howe FA, van den Boogaart A, Griffiths JR, Brown MM: Aging of the adult human brain: in vivo quantitation of metabolite content with proton magnetic resonance spectroscopy. J Magn Reson Imaging 1999, 9:71 I-716.

66. Miller BL: A review of chemical issues in IH NMR spectroscopy: $\mathbf{N}$-acetyl-L-aspartate, creatine and choline. NMR Biomed |99|, 4:47-52.

67. Uren jak J, Williams SR, Gadian DG, Noble M: Specific expression of $\mathbf{N}$-acetylaspartate in neurons, oligodendrocyte-type-2 astrocyte progenitors, and immature oligodendrocytes in vitro. J Neurochem 1992, 59:55-61.

68. Meyerhoff DJ, MacKay S, Bachman L, Poole N, Dillon WP, Weiner MW, Fein G: Reduced brain $\mathbf{N}$-acetylaspartate suggests neuronal loss in cognitively impaired human immunodeficiency virus-seropositive individuals: in vivo I H magnetic resonance spectroscopic imaging. Neurology 1993, 43:509-5I5.

69. Lu ZH, Chakraborty G, Ledeen RW, Yahya D, Wu G: N-Acetylaspartate synthase is bimodally expressed in microsomes and mitochondria of brain. Molecular Brain Research 2004, 122:7|-78.

70. Arnett HA, Fancy SP, Alberta JA, Zhao C, Plant SR, Kaing S, Raine CS Rowitch DH, Franklin RJ, Stiles CD: bHLH transcription factor Olig I is required to repair demyelinated lesions in the CNS. Science 2004, 306:21 III-2II5.

7I. Chang A, Tourtellotte WW, Rudick R, Trapp BD: Premyelinating oligodendrocytes in chronic lesions of multiple sclerosis. $N$ Engl J Med 2002, 346: 165-173.

72. Mulkern RV, Zengingonul HP, Robertson RL, Bogner P, Zou KH, Gudbjartsson H, Guttmann CR, Holtzman D, Kyriakos W, Jolesz FA Maier SE: Multi-component apparent diffusion coefficients in human brain: relationship to spin-lattice relaxation. Magn Reson Med 2000, 44:292-300.

73. Mulkern RV, Gudbjartsson H, Westin CF, Zengingonul HP, Gartner W, Guttmann CR, Robertson RL, Kyriakos W, Schwartz R, Holtzman $D$, Jolesz FA, Maier SE: Multi-component apparent diffusion coefficients in human brain. NMR Biomed 1999, 12:51-62.

74. Beaulieu C: The basis of anisotropic water diffusion in the nervous system - a technical review. NMR Biomed 2002, 15:435-455.

75. Le Bihan D, Mangin JF, Poupon C, Clark CA, Pappata S, Molko N, Chabriat $\mathrm{H}$ : Diffusion tensor imaging: concepts and applications. J Magn Reson Imaging 200I, I 3:534-546.

76. Steen RG, Hamer RM, Lieberman JA: Measurement of brain metabolites by IH magnetic resonance spectroscopy in patients with schizophrenia: a systematic review and metaanalysis. Neuropsychopharmacology 2005, 30:1949-1962.

77. Buchsbaum MS, Friedman J, Buchsbaum BR, Chu KW, Hazlett EA, Newmark R, Schneiderman JS, Torosjan Y, Tang C, Hof PR, Stewart D, Davis KL, Gorman J: Diffusion Tensor Imaging in Schizophrenia. Biol Psychiatry 2006.

78. Steel RM, Bastin ME, McConnell S, Marshall I, Cunningham-Owens DG, Lawrie SM, Johnstone EC, Best JJK: Diffusion tensor imaging (DTI) and proton magnetic resonance spectroscopy (IH MRS) in schizophrenic subjects and normal controls. Psychiatry Research: Neuroimaging 200I, 106(3):161-170.

79. Irwan R, Sijens PE, Potze JH, Oudkerk M: Correlation of proton MR spectroscopy and diffusion tensor imaging. Magn Reson Imaging 2005, 23:85I-858.

80. Sijens PE, Irwan R, Potze JH, Mostert JP, De Keyser J, Oudkerk M: Analysis of the human brain in primary progressive multiple sclerosis with mapping of the spatial distributions using $(I) H$ MR spectroscopy and diffusion tensor imaging. Eur Radio 2005, I 5:1686-1693.

\section{Pre-publication history}

The pre-publication history for this paper can be accessed here:
http://www.biomedcentral.com/1471-244X/7/25/pre pub
Publish with BioMed Central and every scientist can read your work free of charge

"BioMed Central will be the most significant development for disseminating the results of biomedical research in our lifetime. "

Sir Paul Nurse, Cancer Research UK

Your research papers will be:

- available free of charge to the entire biomedical community

- peer reviewed and published immediately upon acceptance

- cited in PubMed and archived on PubMed Central

- yours - you keep the copyright

Submit your manuscript here:

http://www.biomedcentral.com/info/publishing_adv.asp
BioMedcentral 